\title{
Human values, subjective well-being and the metropolitan region
}

\section{Philip S. Morrison \& Mikko Weckroth}

To cite this article: Philip S. Morrison \& Mikko Weckroth (2017): Human values, subjective wellbeing and the metropolitan region, Regional Studies, DOI: 10.1080/00343404.2017.1331036

To link to this article: http://dx.doi.org/10.1080/00343404.2017.1331036

\section{+ View supplementary material $\asymp$}

曲 Published online: 27 Jun 2017.

Submit your article to this journal $\pi$

山 Article views: 46

View Crossmark data 


\title{
Human values, subjective well-being and the metropolitan region
}

\author{
Philip S. Morrison ${ }^{\mathbf{a}}$ () and Mikko Weckroth ${ }^{\mathbf{b}}$ ๑
}

\begin{abstract}
Human values, subjective well-being and the metropolitan region. Regional Studies. Living in a country's largest metropolitan centre has a negative effect on subjective well-being. Although documented in many developed economies, the reasons for this particular geography of well-being are still poorly understood. Meanwhile a separate body of research has shown that the holding of extrinsic or personally focused values is also associated with lower levels of subjective well-being. This paper demonstrates the link between the two. It draws on the European Social Survey (ESS) 2012 to show how metropolitan residents in Finland are more likely to hold extrinsic values such as power and achievement.
\end{abstract}

\section{KEYWORDS}

human values; value dissonance; subjective well-being; life satisfaction; Finland

\section{摘要}

人类价值、主观福祉与大都会区域。Regional Studies. 居住于一个国家中最大型都会区的中心，对于主观福祉有负面 的影响。尽管在诸多已发展经济体中已有所记录, 我们对此般特殊的福祉地理之原因仍理解不足。同时, 另一项独 立的研究显示, 紧握外加的或聚焦个人的价值, 同时关乎较低程度的主观福祉。本文将証实两者之间的关联性。本 文运用2012年的欧洲社会调查，展现芬兰的大都会居民如何更可能紧握诸如权力与成就等外加的价值。

关键词

人类价值; 价值不一致; 主观福祉; 生活满意度; 芬兰

\section{RÉSUMÉ}

Les valeurs humaines, le bien-être subjectif et la zone métropolitaine. Regional Studies. Habiter la plus grande zone métropolitaine d'un pays a des retombées négatives sur le bien-être subjectif. Les raisons qui expliquent cette géographie particulière du bien-être sont mal comprises, bien qu'elles soient bien documentées dans beaucoup des pays développés. Entre-temps, un autre corpus de recherche a démontré que s'en tenir à certaines valeurs extrinsèques ou spécifiques à l'individu s'associe aussi à des niveaux de bien-être subjectif moins élevés. Cet article démontre le lien entre les deux. II puise dans l'Enquête sociale européenne 2012 afin de montrer comment les habitants des zones métropolitaines en Finlande sont plus susceptibles de s'en tenir à des valeurs extrinsèques, telles le pouvoir et le sentiment de satisfaction.

\section{MOTS-CLÉS}

valeurs humaines; discordance des valeurs; bien-être subjectif; satisfaction dans la vie; Finlande

\section{ZUSAMMENFASSUNG}

Menschliche Werte, subjektives Wohlbefinden und die Metropolitanregion. Regional Studies. Das Leben im größten metropolitanen Zentrum eines Landes wirkt sich negativ auf das subjektive Wohlbefinden aus. Diese besondere Geografie des Wohlbefindens wurde zwar in zahlreichen Industrieländern dokumentiert, doch ihre Gründe sind

\section{CONTACT}

a philip.morrison@vuw.ac.nz

School of Geography, Environment and Earth Sciences, Victoria University of Wellington, Wellington, New Zealand.

b(Corresponding author) mikko.weckroth@helsinki.fi

Department of Geosciences and Geography, Division of Urban Geography and Regional Studies, University of Helsinki, Helsinki, Finland. 
weiterhin unzureichend erforscht. Gleichzeitig verdeutlichen separate Studien, dass die Orientierung an extrinsischen oder persönlich fokussierten Werten ebenfalls mit einem niedrigeren Maß an subjektivem Wohlbefinden einhergeht. In diesem Beitrag wird der Zusammenhang zwischen den beiden Phänomenen nachgewiesen. Ausgehend von der europäischen Sozialstudie von 2012 wird gezeigt, wie sich Metropolitanbewohner in Finnland häufiger an extrinsischen Werten wie Macht und Leistung orientieren.

\section{SCHLÜSSELWÖRTER}

menschliche Werte; Wertedissonanz; subjektives Wohlbefinden; Lebenszufriedenheit; Finnland

\section{RESUMEN}

Valores humanos, bienestar subjetivo y la región metropolitana. Regional Studies. Vivir en el centro metropolitano más grande de un país tiene un efecto negativo en el bienestar subjetivo. Aunque esta geografía particular de bienestar se ha documentado en muchas economías desarrolladas, todavía no se acaban de entender bien sus motivos. Asimismo en un campo de investigación separado, se ha demostrado que la orientación por valores extrínsecos o centrados personalmente también se asocia a niveles inferiores de bienestar subjetivo. En este artículo demostramos la relación entre estos dos fenómenos. A partir de la Encuesta Social Europea de 2012 mostramos cómo los residentes metropolitanos en Finlandia son más propensos a orientarse por valores extrínsecos, tales como poder y éxito.

PALABRAS CLAVES

valores humanos; disonancia de valores; bienestar subjetivo; satisfacción con la vida; Finlandia

JEL R11, R13

HISTORY Received 5 February 2016; in revised form 8 May 2017

\section{INTRODUCTION}

The collection of measures of subjective well-being across the globe was stimulated almost a decade ago by the publication of the Stiglitz Report (Stiglitz, Sen, \& Fitoussi, 2009). The primary purpose of the report was to supplement national accounts with measures of the value people place on those important transactions in life which do not take place through the market. The policy interest in subjective well-being was initially taken up by national governments, but in more recent years a large number of initiatives have appeared at the level of the region, the city and the local community. ${ }^{1}$

The road has not been an easy one and there is still vigorous debate over the most appropriate measures of wellbeing and the values that lie behind them (Jordan, 2008), and no settled consensus on the meaning of well-being has yet emerged beyond its use in the vernacular (Gough \& Arlister McGregor, 2007, p. 5). There is still no general agreement on what measure(s) of well-being should guide public policy because defining well-being is ultimately a political project (Scott, 2012) and remains 'a wicked problem' in public policy terms (Bache, Reardon, \& Anand, 2016). Nevertheless, we now are more aware of the differences between objective and subjective well-being and the relationship between the two (Searle, 2008) and of the properties of the commonly used cognitive measure - life satisfaction.

Although population size or density per hectare is not inevitably correlated to lower subjective well-being, we do know that average life satisfaction is typically lower among those living in most countries' very largest urban centres. The evidence comes from studies in a range of developed economies including the United States (Berry
\& Okulicz-Kozaryn, 2011, 2009; Valdmanis, 2015), Canada (Lu, Schellenberg, Hou, \& Helliwell, 2015), Australia (Cummins, Davern, Okerstrom, Lo, \& Eckersley, 2005; Shields \&Wooden, 2003), New Zealand (Morrison, 2007, 2011), Britain (Ballas, 2008; Ballas \& Tranmer, 2012; Smarts, 2012), Ireland (Brereton, Clinch, \& Ferreira, 2008), and Scotland (Dunlop, Davies, \& Swales, 2016). ${ }^{2}$

More recent confirmations of this same negative relationship are now emerging from continental Europe (Aslam \& Corrado, 2012; European Commission, 2013; Lenzi \& Perucca, 2016b; Lenzi \& Perucca, 2016c; Piper, 2015; Pittau, Zelli, \& Gelman, 2010), as well as some on individual countries such as Romania (Lenzi \& Perucca, 2016a) and Germany (Botzen, 2016). Similar findings are now emerging in China (Chen, Davis, Wu, \& Dai, 2015) and Hong Kong (Schwanen \& Wang, 2014). On the basis of this evidence, the issue is no longer whether subjective well-being is lower in the largest cities of the developed world but why. One of the reasons we suggest in this paper is that residents in metropolitan centres disproportionately identify with those specific human values which correlate negatively with subjective well-being.

\section{Outline}

The paper is structured as follows. The next section reviews the sociological roots and introduces a typology of human values. In order to link well-being and values with location, we introduce the concept of 'environmental fit'. This is followed by our rationale for the Finland case study. We then offer four hypotheses: (1) that life satisfaction is correlated with the values people hold; (2) that metropolitan residents are more likely to identify with extrinsic or personally focused values; (3) that the negative 
effect on well-being of values such as power and achievement are mediated by metropolitan residence; and (4) that people's subjective well-being is related to how closely their values approximate the community norm (value dissonance). The paper concludes with a recommendation that the evidence for Finland be extended to comparisons of metropolitan and non-metropolitan regions in other European countries covered by the European Social Survey $(\mathrm{ESS}) .^{3}$

\section{SOCIOLOGICAL ROOTS}

Students of sociology will be quick to point out that differentiating the nature of social interaction in rural and urban areas has deep roots, going back at least to Ferdinand Tönnies who drew the distinction between gemeinschaft and gesellschaft, translated as community and society, respectively (Tönnies, 1887). According to this conceptual dichotomy, 'community' is characterized by personal social interactions, along with the roles, values and beliefs based on such interactions. 'Society', on the other hand, is characterized by indirect interactions, impersonal roles, formal values and beliefs based on such interactions. As such, rural areas and relatively small settlements were believed to display intense patterns of social contact in small, tightly knit social networks, whereas urban areas were characterized by more diverse and transient contact patterns, with relatively few intense relationships. ${ }^{4}$

As a conceptual distinction the difference between 'community' and 'society' did not necessarily carry any connotations of subjective well-being in the sense that this term is understood today. One could argue, however, that well-being assumed a prominent place in Louis Wirth's characterization of urbanism as a way of life, even if the terms he used in the 1930s differ from those of today (Guterman, 1969; Simmel, 1976; Wirth, 1969). According to Fisher, 'Classic urban sociology ... argues that the complex differentiation of urban social structure leads to an anomic society of isolated individuals who suffer alienation and deviance' (Fischer, 1973, p. 221).

What was not explicit either in Wirth or the many commentators who followed is any formal demonstration that values prevailing in rural and urban societies were related to differences in subjective well-being. Writing in the second decade of the 2000s we have a wider range of conceptual tools and much richer database with which to address such questions. Drawing on both, our contribution to the above literature is to show that in the 21st century there are demonstrable value differences between metropolitan and non-metropolitan societies, and that there is a linkage between these values and differences in their average levels of subjective well-being. What is less clear from our analysis is whether living in the metropolis might moderate the negative effect of extrinsic values such as power and achievement.

\section{HUMAN VALUES}

Values function as standards that guide thought and action and individuals employ these to judge themselves and others (Lindeman \& Verkasalo, 2005, p. 170). Several classifications of values have been proposed and two of the best known, Inglehart (1990) and Schwartz (1992), both have their strengths and weaknesses (Dobewall \& Strack, 2014; Gasper, 2007). In this study we draw on the universal human value scale developed by Shalom Schwartz because it has been integrated into the sixth (2012) round of ESS from which we draw our measure of life satisfaction and covariates (ESS, 2012). ${ }^{5}$

In order to construct the Schwartz value scale, each respondent is asked to position themselves on a 1-6 scale with respect to 21 value items. Their responses are then used to construct the 10 values that Schwartz organizes into a diagram he calls a circumplex (reproduced here as Figure 1). The circumplex is designed to contrast a concern for others (self-transcendence) and the self (self-enhancement) as well as the tension between openness to change and conservatism. ${ }^{6}$ It is organized so that the strength of positive association between each pair of values decreases with the distance between them (Schwartz, 2004, p. 230). Of particular interest in our study is the relationship between those extrinsic values with a personal focus

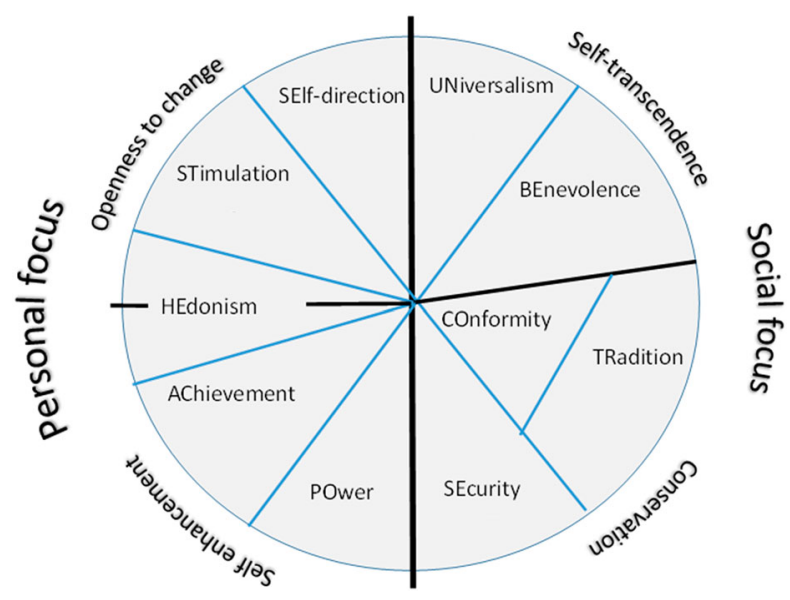

Figure 1. Theoretical model of relations among 10 motivational types of value.

Note: There is a tendency among many respondents to utilize only one end of the scale (Sortheix, Olakivi, \& Helkama, 2013). Moreover, individuals and cultural groups often differ in their use of the item response scale, and these differences can distort findings and lead to incorrect conclusions (Schwartz, 2012). In order to correct for these individual differences, Schwartz recommends centring or normalizing on the individuals score over all 21 items. These centred responses are then averaged over two items (in most cases) in order to construct each value. This involves calculating the respondent's mean score $(M)$ over all 21 items, $M_{i}=(1 / 21) * \sum_{r=1}^{R} r_{i}$, and subtracting this from their responses to each item to generate an individually centred response: $c r_{i}=r_{i}-M_{i}$, where $c r$ 'represents the relative importance of each value type in relation to the other value types' (Schwartz, 2012, p. 2).

Source: After Schwartz (2012, p. 9, fig. 1). 
on the left of the circumplex, and those intrinsic values with a social focus on the right. ${ }^{7}$

\section{VALUES AND WELL-BEING}

As constructed, the human values circumplex says nothing about subjective well-being. However as Lyubomirsky et al. have argued, values should be taken into consideration as components of well-being (Lyubomirsky, Sheldon, \& Schkade, 2005), a point later echoed by others (e.g., Bobowik, Basabe, Paez, Jimenez-Aristizabal, \& Bilbao, 2011; Jarden, 2010). In order to substantiate their case, Bobowik et al. (2011) drew on the 2006 ESS to support the distinction between well-being promoting and wellbeing impeding values as derived from self-determination theory (Ryan \& Deci, 2000). The literature addressing the relationship between values and well-being suggests that extrinsic values such as security, power and tradition are associated with lower life satisfaction (Huppert, 2009; Kasser \& Ahuyvia, 2002) and intrinsic values such as selfdirection, hedonism and stimulation with relatively higher levels of subjective well-being (Bobowik et al., 2011). ${ }^{8}$

For our subjective well-being measure we draw on the most frequently used cognitive measure of subjective well-being: life satisfaction. Life satisfaction in the ESS is captured in responses to the question: 'All things considered, how satisfied are you with your life as a whole nowadays?' The scale ranges from 0 , extremely dissatisfied, to 10 , extremely satisfied (ESS, 2006). Such a measure is conceptually and empirically distinct from the term 'happiness', which is a measure of short-term affect or mood (Helliwell, Layard, \& Sachs, 2015).

There is now a consensus about the way in which readily measurable attributes of people are correlated with the above measure of subjective well-being (Frey \& Stutzer, 2002; Helliwell, Layard, \& Sachs, 2013). Those attributes typically include sex, age, health, marital status, children at home, years of education, household income, as well as indicators of activity such as paid work, education, unemployment, looking for work and being in retirement. We employ each of these controls in our regression of wellbeing on values (see Appendix A in the Supplemental data online).

In summary, we have suggested that values should be included as arguments in studies of subjective well-being as identified in the Schwartz value scale included in the sixth round of the ESS, 2012. We show below how these values are distributed differently in metropolitan and non-metropolitan areas, and how this contributes to the lower level of life satisfaction we witness in metropolitan regions. As part of this same argument, we also ask whether metropolitan residence moderates the effect of values on subjective well-being.

\section{ENVIRONMENTAL FIT}

In order to address the influence of metropolitan residence on subjective well-being, we draw on a concept that has received only limited attention in the regional studies/ science literature: environmental fit. The essential idea behind this concept is that when the numerous factors that otherwise contribute to psychological well-being are held constant, 'people who match their cultural environment will experience better psychological well-being than people who do not' (Fulmer, Gelfand, Kruglanski, \& Al, 2010, p. 1568). The associated literature explores the way in which the social and physical context in which one lives can amplify features of one's personality in ways that are positive or negative for individual well-being (Higgins, 2005). The prevailing finding is that people judge their decisions to be better when there is a closer matching between the person and their environment (Hardin \& Higgins, 1996), and hence when there is greater 'regulatory fit' (Higgins, 2000). ${ }^{9}$

The scale at which spatial sorting maximizes environmental fit is still a matter of debate, but Park and Peterson (2010) make a persuasive case for the city as the appropriate level of organization, notwithstanding differences in cities' physical scale and complexity. As a result of searching for environments that maximize their environmental fit people sort themselves spatially (Plaut, Lachman, \& Markus, 2002) according to their personal values (Motyl, Iyer, Oishi, Trawalter, \& Nosek, 2014), personal attitudes and attributes (Tam Cho, Gimpel, \& Hui, 2013). It follows that personality also helps predict migration (Jokela, 2009, 2013) and that the search for environmental fit results in residential segregation (Rentfrow, Gosling, \& Potter, 2008). ${ }^{10}$

The particular set of values that prevail in a place influence how people feel in that environment - whether they feel 'at home' or 'out of place' (Sagiv \& Schwartz, 2000). ${ }^{11}$ When peoples' personal values match the prevailing values in the environment, they are more likely to be able to pursue those goals that they believe will satisfy their internal need for growth and self-actualization. It follows that being among those with shared values is more likely to lead to higher levels of cognitive well-being (Sagiv \& Schwartz, 2000, p. 343).

In summary, the central point made in environmental psychology and cognate literatures is that one's subjective well-being is not simply a function of one's personal attributes, ascribed or achieved, but also depends on how well they 'fit in'. Other things equal, the closer the environmental fit, the higher a person's satisfaction with life (Sagiv, Roccas, \& Hazan, 2004). We now seek empirical evidence by drawing on the Finnish experience.

\section{THE CASE OF FINLAND}

We have chosen Finland as our case study because of the rapid growth of an industrial/service complex in the Helsinki-Uusimaa region. Finland was transformed from a rural periphery at the beginning of 20th century to a modern knowledge-intensive society and a global leader in the information and communication technology (ICT) sectors at the beginning of 21st century (Ojala, Eloranta, \& Jalava, 2007). The urbanization that accompanied this structural shift occurred more rapidly in Finland than in continental 
Europe (e.g., Moisio \& Paasi, 2013). The Helsinki-Uusimaa region emerged as the dominant core region, which henceforth is referred to here as 'metropolitan Finland' in contrast to 'non-metropolitan Finland. ${ }^{12}$

While referring to the Helsinki-Uusimaa region as metropolitan Finland serves as a valuable short hand, it is important to note that only about two-fifths of this region's inhabitants actually see themselves as residents of 'a big city'; a further one-fifth say they live in the suburbs or outskirts, and only slightly fewer place themselves in a 'town or small city'. Despite the mix of densities, the overall level of urbanization is much higher than experienced by those living in the rest of Finland, the majority of whom live in either towns or small cities (one-third), country villages (one-fifth) or farms or homes in the country (onequarter). ${ }^{13}$

Most people in developed economies are satisfied with their lives and the typical distribution of life satisfaction is negatively skewed. In the Finnish case, just under half the sample rate their life satisfaction below 8 on the 11-point life satisfaction scale and just over half rate above $8 .{ }^{14}$ Although average levels of life satisfaction differ among the five different settlement categories listed above, none of their pair-wise differences is statistically significant. Therefore, we confine our comparisons of subjective wellbeing to the difference between metropolitan and nonmetropolitan Finland.

\section{HYPOTHESES}

We advance four interconnected hypotheses. The first is that life satisfaction varies with the values people hold, as demonstrated by Bobowik, Paez, and Basabe (2014b). We complement this idea with a second hypothesis: that metropolitan residents are more likely to hold selfenhancement values (power and achievement) and that socially oriented self-transcendence values (benevolence and conformity) are more likely to be characteristic of those living in non-metropolitan areas. Other things equal, this result alone implies that residents of the metropolis exhibit lower levels of well-being.

We then venture a third hypothesis and test whether the negative effect of extrinsic values on subjective wellbeing is moderated by metropolitan residence, the hypothesis being that the higher the proportion holding extrinsic values in metropolitan Finland the lower their negative effect on subjective well-being. On the basis of the same argument, we also test whether the negative effect of extrinsic values on subjective well-being is inflated in non-metropolitan environments because of lack of environmental fit, i.e., a smaller proportion of their population holding such values.

Our fourth hypothesis is that subjective well-being will be sensitive to the difference in the intensity with which people hold their values relative to the average in their region (value dissonance). People hold each of the 10 individual values in Figure 1 with varying intensity.

In order to keep the project manageable we select just two pairs of values from each side of the circumplex: power and achievement from the left and benevolence and conformity from the right. We have selected these because power and achievement are motivated by social superiority and esteem whereas benevolence and conformity are associated with normative behaviour that promotes close relationships (Schwartz, 2012, p. 9).

The value labelled 'benevolence' is constructed from the average of responses to two statements (survey items): it is 'Important to help people and care for others' well-being,' and it is 'Important to be loyal to friends and devote to people close.' The value labelled 'conformity' is the average of responses to the following two statements: it is 'Important to do what is told and follow rules' and ' ... to behave properly'. Power, in turn, is the average of the degree to which one believes it is, 'Important to be rich, have money and expensive things' and it is 'Important to get respect from others.' The value 'achievement' is based on the degree to which the respondent believes it is 'Important to show abilities and be admired' and 'Important to be successful and that people recognise achievements.'

People identify most closely with values such as benevolence and conservatism which have a social focus and therefore scores on these values bunch towards the top of the one-to-six value scale (a negatively skewed distribution), which means they return a higher average score and exhibit a more negatively skewed distribution of responses. ${ }^{15}$ Other values such as stimulation and hedonism exhibit responses that are symmetrically distributed by comparison and have a higher variance. By contrast, those extrinsic values with their strong personal focus such as power, achievement and stimulation attract a smaller population as evidenced by their positively skewed distribution and lower mean level of identification.

The first and third of our hypotheses can be tested by modelling life satisfaction as a linear function of metropolitan residence, the level of relative identification with one of the four values, the interaction between metropolitan residence and one of the four values while controlling for a vector of covariates. The following equation is applied, one value at a time:

$$
S_{i j}=\alpha_{o}+\gamma J_{i j}+\zeta V_{i j}+\delta J \cdot V_{i j}+\beta X_{i j}+\varepsilon_{i j}
$$

where $S_{i j}$ is the satisfaction with life score reported by the $i$ th person resident in the $j$-th region.

Based on the extensive literature showing the negative effect of living in large metropolitan centres, we expect life satisfaction to regress negatively on metropolitan Finland $(J=1)$ compared with non-metropolitan Finland and hence that $\gamma($ gamma $)<0$. Estimation is via ordinary least squares (OLS). ${ }^{16}$

We test our first hypothesis using the second term in equation (1), $V_{i j}$, the value of interest. We expect life satisfaction to regress positively when the value is benevolence or conformity, $\zeta$ (zeta) $>0$, and negatively when the value is power or achievement, $\zeta<0$. Our second hypothesis, that metropolitan residents are more likely to hold extrinsic values, we specify separately below along with our value dissonance hypothesis. 
Testing the third hypothesis requires the interaction term, $J \cdot V$, the degree to which being a resident of metropolitan Finland might moderate the effect of holding a given value. According to the environmental fit hypothesis, we expect the interaction terms to be negative, $\delta<0$ when the values are benevolence or conformity and to be positive, $\delta>0$ when the values are power or achievement (because a greater proportion holding such values in metropolitan environments would, a priori, suggest a closer 'environmental fit').

Finally, the vector of parameter estimates $\beta$ (beta) are obtained from the cross-sectional association of subjective well-being with the covariates listed in Appendix A in the supplemental data online. The random error term is $\varepsilon$ (epsilon) and, since we anticipate heteroskedasticity, all parameters are estimated with robust standard errors. ${ }^{17}$

\section{RESULTS}

Our estimates of the parameters in equation (1) are shown in Table 1 for each of the four values. The estimates of $\gamma$ in the first line confirm our expectation going into this studythat residents of metropolitan Finland would return lower levels of subjective well-being than their non-metropolitan counterparts. Well-being in metropolitan Finland falls between 0.18 and 0.21 of one unit on the 11-point subjective well-being scale, depending on which value is included. There is one exception however. The value 'power' has no apparent effect on subjective well-being when also interacted with metropolitan Finland $(\delta=0.10)$.

The second line of Table 1 reports the test of our first hypothesis, namely that subjective well-being varies with the values people hold. The estimates of parameter $\zeta$ is positive when the two values with a social focus are dominant (benevolence and conformity) and negative when people identify more strongly with values that have a personal focus (power and achievement). These results accord with recent studies of these relationships (Bobowik et al., 2014b; Jarden, 2010).

Our second hypothesis was that metropolitan residents would be more likely to hold self-enhancement (extrinsic) values - those on the left-hand side of the circumplex as represented here by power and achievement. We tested this outside the confines of Table 1 and a series of $t$ tests. For example, the mean individually centred score for power is higher in metropolitan Finland, -1.35 < $-1.26(t=-2.02, p=0.05)$. A similar result held in the case of achievement which metropolitan residents also identify more closely with, although not to the same degree: $-0.76<0.71$ or level of significance $(t=-1.21)$.

Our third hypotheses asks whether metropolitan residence offers a more favourable environmental fit for those who hold extrinsic values because they share those values with a larger proportion of local residents. The estimated signs in Table 1 are consistent with such an expectation. The coefficient on the interaction term $J \cdot V$ is positive $(\delta$ $>0)$ when power and achievement were interacted with metropolitan residence and negative when benevolence and conformity are interacted with metropolitan residence $(\delta<0)$. However, with the main effects of region and value also in the model, along with controls (and our use of robust standard errors), none of these estimates of $\delta$ is statistically significant. This suggests that while holding extrinsic values is accompanied by lower subjective wellbeing, and so too is residence in Helsinki-Uusimaa region, residing in metropolitan Finland is insufficient to reduce significantly the negative effect of holding these extrinsic values. Statistically speaking, the environmental fit of metropolitan residence is neutral when it comes to the negative effect of power and achievement on subjective well-being. We draw the same conclusion when it comes to the effect of non-metropolitan residence on the way intrinsic values affect well-being.

Our fourth hypothesis addresses value dissonance: how people's subjective well-being is affected by the difference between how strongly they hold a given value relative to the average for their community.

\section{VALUE DISSONANCE}

We expected those who identify less strongly with those social values that are characteristic of their community to exhibit relatively lower levels of life satisfaction, a response we refer to as value dissonance. A priori we expected this dissonance would be greater in non-metropolitan Finland where a higher priority is placed on conformity and benevolence and hence on community norms. We test this by plotting the predicted mean levels of life satisfaction generated by the quadratic versions of equation (1) on each of the four values, panel by panel in Figure 2. The $y$-axis in each panel carries the predicted level of life satisfaction from equation (1) and the $x$-axis captures the national distribution of each value after the value has been centred on the national mean (for details, see the note to Figure 1).

The interior of each panel positions and contrasts the way life satisfaction changes with the relative strength with which people hold each value. The solid vertical line in each panel refers to the individually centred value in metropolitan Finland and the thin vertical lines to nonmetropolitan Finland. In the case of the benevolence panel the bold metropolitan value completely covers and is therefore visually indistinguishable from the non-metropolitan value. The conformity panel offers a clearer contrast and in this case the centred individual values for nonmetropolitan Finland (the thin continuous vertical line) sits to the right of the metropolitan and very close to the national average for all values (0). In the remaining two panels, power and achievement, we see the metropolitan average sitting to the right of the non-metropolitan, while both sit well to the left of the national case depicting all values.

In panel 1 of Figure 2 we witness most individuals evaluating benevolence more positively than the other values in the circumplex (the national mean, 0). Panel 2 shows that identification with conformity is much closer to the way people identify with all values. By contrast, relatively few people identify closely with power which therefore sits to the left of the national mean for all values (0). To a lesser 
Table 1. Estimated associations of four values on life satisfaction in the presence of metropolitan residence and socio-economic controls.

\begin{tabular}{|c|c|c|c|c|}
\hline Variable & Benevolence & Conformity & Power & Achievement \\
\hline \multirow[t]{2}{*}{ Metropolitan (J) } & -0.19 & -0.21 & -0.09 & -0.18 \\
\hline & -1.57 & -3.39 & -0.80 & -2.23 \\
\hline \multirow[t]{2}{*}{ Value $(V)$} & 0.18 & 0.10 & -0.15 & -0.09 \\
\hline & 3.06 & 2.52 & -3.58 & -2.34 \\
\hline \multirow[t]{2}{*}{ Interaction $\left(J^{*} V\right)$} & -0.03 & -0.03 & 0.10 & 0.05 \\
\hline & -0.27 & -0.40 & 1.40 & 0.74 \\
\hline Controls $(X)$ & Yes & Yes & Yes & Yes \\
\hline \multirow[t]{2}{*}{ Constant } & 5.66 & 5.98 & 5.59 & 5.86 \\
\hline & 6.24 & 6.47 & 5.97 & 6.32 \\
\hline Observations & 1993 & 1993 & 1993 & 1993 \\
\hline$R^{2}$ & 0.16 & 0.16 & 0.16 & 0.16 \\
\hline
\end{tabular}

Notes: Robust standard errors are used.

Design weights were applied as recommended in https://www.europeansocialsurvey.org/docs/methodology/ESS_weighting_data_1.pdf.

$T$-statistics are shown in italics.

Data are from Finland, 2012.

degree this is also true of people's scores on the achievement value.

The final statistic represented in Figure 2 is the standard deviation (SD). The purpose of representing the SD is to help focus on the majority of cases in each panel those that sit between \pm 1 SD. With the above graphical infrastructure in place we can now inspect for differences in the way average predicted life satisfaction changes as the level of value identification deviates from their regional average - our measure of value dissonance.

The two plotted lines running horizontally across each panel indicate the way average levels of (predicted) life satisfaction change with distance from the regional norm. Filled circles denote those resident in metropolitan Finland and the open squares those in non-metropolitan Finland. A comparison of the two lines in each panel reminds us, firstly, of the lower life satisfaction of metropolitan residents. In both parts of Finland average life satisfaction rises the closer people identify with benevolence (top left panel in Figure 2).

In the conformity panel, well-being among metropolitan and non-metropolitan residents departs more obviously as conformity values rise. Focusing on the majority case, the area between $\pm 2 \mathrm{SD}$ from the means of the two regions, we observe well-being rising among non-metropolitan residents as a person's identification with conformity gets closer to the regional norm. By contrast, there is little such evidence in the metropolitan Finland. In fact the converse ('U'-shaped) characteristics of metropolitan residents suggests that when it comes to conformity, well-being rises the further an individual departs from the metropolitan norm. Such a result is consistent with the thesis that population in metropolitan region is more likely to attract and retain those with unconventional, the 'deviant' or non-conformist values.

The two values with a personal focus in Figure 2, power and achievement, also exhibit a 'U' shape which implies a reverse value dissonance. In both cases they are associated with levels of well-being which are much lower than the country average. In the power panel the bold solid vertical line indicating metropolitan Finland sits to the right of the non-metropolitan line $(-1.26>-1.35)$ as it does in the achievement panel $(-0.71>-0.77)$. These representative values from the left of the value circumplex of Figure 1 behave differently as people's identification with them becomes stronger. Life satisfaction falls as the mean of each region is approached. The more closely people identify with power and achievement the lower their life satisfaction, but only when people identify with these values to a much greater degree than the average in their region. Far from exhibiting value dissonance, therefore, when it comes to those extrinsic values people's well-being actually rises the weaker their identification with their regional average.

To summarize, after establishing that subjective wellbeing is lower in metropolitan Finland, our analysis confirmed that identification with extrinsic values is associated with lower levels of well-being. Given that those with extrinsic values are more attracted to metropolitan Finland, we hypothesized that holding such values in HelsinkiUusimaa might reduce their negative effect on subjective well-being because of closer environmental fit. Although the signs of the estimates supported this expectation, the $t$-statistics were not strong enough categorically to infer such an effect. We can not conclude, therefore, that living in metropolitan Finland weakens the negative effect of power and achievement on well-being.

Finally, with respect to our fourth hypothesis, value dissonance, we found that people who identified more strongly with intrinsic values were more sensitive to how far their own value identification was from the average in their region. Their average predicted levels of subjective well-being rose the closer their own value identification approach their regional norm. The reverse result held by metropolitan residents holding conformist values. Similarly, we found little evidence of value dissonance when it comes to extrinsic values. Those identifying strongly with power and achievement actually experienced a fall in 

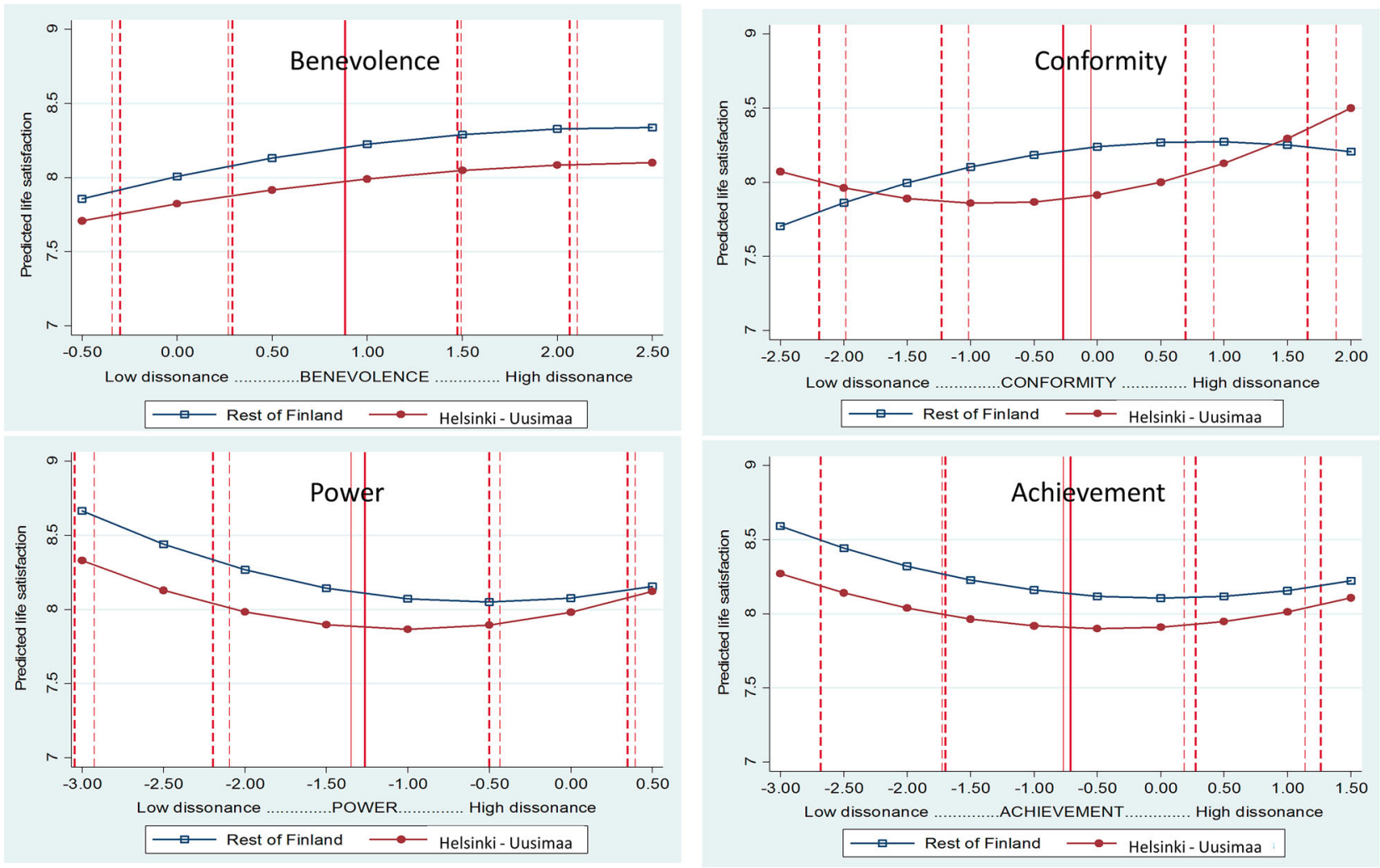

Figure 2. Life satisfaction and relative value identification in metropolitan (Helsinki-Uusimaa) and non-metropolitan (rest of Finland) contexts.

Source: European Social Survey (ESS) (2012).

subjective well-being as their level of identification approached the average in their region and here there was little difference here between those living in metropolitan and non-metropolitan Finland.

\section{CONCLUSIONS}

This paper has been motivated by the well-documented negative relationship between subjective well-being and residence in the largest metropolitan centre of a developed economy. Despite the fact that many countries' largest centres are the main generators of employment and growth, their residents report lower levels of well-being than those living in smaller settlements. This generic finding which applies to Europe in general also applies to Finland, which we have used as our case study.

As far as we can tell, no previous studies investigating the negative effect of metropolitan residence on life satisfaction have taken human values into account in a model of well-being. In order to explore the possible role of human values, we secured our measures of life satisfaction from the sixth round of ESS 2012, along with supplementary questions on human values categorized according to the Schwartz human value scale.

We confirmed the presence of statistically significant differences in average life satisfaction between metropolitan Finland (the Helsinki-Uusimaa region) and non-metropolitan Finland (the rest of Finland) as expected. We also registered the expected negative association between well- being and the holding of extrinsic values. We went on to show how population in metropolitan Finland is made up of individuals with extrinsic and personally focused values such as power and achievement. ${ }^{18}$ By contrast, residents of non-metropolitan Finland were more likely to identify with intrinsic community or socially focused values such as benevolence and conformity, both of which are positively correlated with subjective well-being.

The literature on environmental fit suggested that raising the proportion of a local population holding extrinsic values might lower those residents' negative association with well-being, but we were unable to demonstrate this empirically despite obtaining signs consistent with this hypothesis. We employed a second concept, value dissonance, in order to throw further light on the way values might differentially condition subjective well-being in metropolitan and non-metropolitan Finland. We found that holding intrinsic values increased the negative impact that deviations from the 'community norm' had in nonmetropolitan settings, whereas the reverse applied in metropolitan Finland where non-conformist values were stronger.

To return to the motivation for this study, our Finnish evidence suggests that the interface between values, wellbeing and the metropolitan environment might help explain, in part at least, why our largest metropolitan areas continue to return lower levels of subjective well-being than the country average. We observed a relative lack of environmental fit in the sense that the proximity of others with like values does not appear to weaken this negative association. 
A further dimension that deserves attention is the heterogeneity of responses. Our paper has focused on the average, but there is a case for examining the way different subgroups of the population may behave and the application of equation (1) to these subsets may yield dividends in future work.

To conclude, our explorations endorse Becchetti et al.'s point that: 'The importance of human values and relational life for economic health and subjective well-being is still largely underestimated, and is a fascinating field for future research' (Becchetti, Bruni, \& Zamagni, 2015, p. 133). Certainly our study opens up opportunities for testing these ideas on a range of other European countries.

\section{ACKNOWLEDGEMENTS}

An early draft of the paper was presented by the authors at the 55th European Regional Science Association (ERSA) Congress in Lisbon, Portugal, August 2015, under the title 'Capturing effects of cities on subjective wellbeing'. We thank the participants for their comments at the special session entitled 'Regional well-being: measurement, analysis and policy practices'. We also acknowledge the valuable suggestions made by Judd Ormsby and Dr Arthur Grimes of Motu Economic and Public Policy Research, New Zealand, on an initial draft in March and April 2016. The authors also appreciated the encouraging and apposite comments made by the editor of Regional Studies and three anonymous referees. The responsibility for the published paper lies with the authors alone.

\section{DISCLOSURE STATEMENT}

No potential conflict of interest was reported by the authors.

\section{NOTES}

1. Geographical variations in well-being are summarized periodically in the World Happiness Reports (Helliwell, Layard, \& Sachs, 2011, 2013, 2015). Several international reviews have also kept this issue in front of policy-makers (e.g., European Commission, 2013; Albouy, 2008; Lagas, Van Dongen, Van Rin, \& Visser, 2015). Recent reviews of subjective well-being research at the level of the region include Morrison (2014), Organisation for Economic Co-operation and Development (OECD) (2014) and Tomaney (2015).

2. The authors are aware of only two studies that have been unable to identify negative effects of big city living on well-being: Albouy (2008) and Itaba (2016). The first was based on objective quality-of-life estimates (in US cities) rather than subjective well-being. While the second was based on subjective measures of happiness across Japanese cities it was unable to identify separately the largest cities where much lower levels of life satisfaction are typically detected.
3. For details of the survey, see http://www.europeansocial survey.org/about/index.html. For details of the Human Values module in ESS12, see: http://www.europeansocial survey.org/data/themes.html?t=values. The Schwartz scale has been tested in many countries and the configural and metric invariance tests hold up well in the Finnish sample on which we draw here (Davidov, Schmidt, \& Schwartz, 2008).

4. The concepts Gemeinschaft and Gesellschaft were also used by Max Weber, who, writing in response to Tönnies, argued that Gemeinschaft was rooted in a 'subjective feeling', whereas Gesellschaft-based relationships were rooted in 'rational agreement by mutual consent' (Weber, 1921).

5. The ESS employs a shorter version of the original Schwartz Human Values Scale. In the Supplementary (Human Values Scale) Section G of the ESS6, each respondent positions themselves on a 1-6 ordinal scale with respect to 21 separate statements. For example, the interviewer presents (male respondents in this example) with the following statement:

\footnotetext{
Now I will briefly describe some people. Please listen to each description and tell me how much each person is or is not like you. The first statement on the card is A, as follows: 'Thinking up new ideas and being creative is important to him. He likes to do things in his own original way.' The respondent then selects one of the following six response options. The statement is 01 Very much like me, 02 Like me, 03 Somewhat like me, 04 A little like me, 05 Not like me or 06 Not like me at all, 88 (Don't know).
}

6. For related discussions and interpretations of the Human Values Scale, see Huppert (2009). For other applications and discussion of the adjustment procedure, see Lindeman and Verkasalo (2005).

7. By selecting only two values from either side of the circumplex we are removing some of the complexity involved in the set of right-hand-side 'extrinsic' values. While this is necessary in order to generate a manageable argument, it is important to recognize what is not being considered. It would be possible for someone to exercise benevolence and conformity within their group but to exhibit weak levels of Universalism, for example, and be less than hospitable to particular minority groups including in-migrants. Benevolence might well strengthen the in-group, but at the expense of the out-group. (We are indebted to the editor for drawing our attention to this point.)

8. These findings of a positive role of intrinsic and a negative role of extrinsic ones are consistent with previous studies (Sagiv \& Schwartz, 2000; Kasser \& Ahuyvia, 2002; Schmuck, Kasser, \& Ryan, 2000; Sheldon et al., 2004; Vansteenkiste, Duriez, Simons, \& Soenens, 2006; Bobowik et al., 2011).

9. The role of psychological traits only made a brief appearance in the geographical literature some 30 years ago (Kitchin, 1997). The more recent focus on the geographical dimensions of psychological traits has come not from geographers but from psychologists (Rentfrow, 2014). This recent literature uses the term 'geographical 
psychology' and begins with the presumption that 'social and physical characteristics of the environment significantly affect health, wellbeing, attitudes, and identity - constructs at the core of psychology' (p. 3). The aim of geographical psychology is to identify how the places in which we live contribute to our psychological development. As such, 'geographical psychology attempts to bridge research across areas of psychology and other disciplines by investigating the spatial organization and geographical representation of psychological phenomena and the mechanisms guiding those processes' (p. 5).

10. Studies using a range of methodologies now provide support for the notion of 'value environment congruence' (Oishi, Diener, Lucas, \& Suh, 1999; Lonnqvist, Walkowitz, Wichardt, Lindeman, \& Verkasalo, 2009; Lun, Kesebir, \& Oishi, 2008). Sharing the same values as proximate others contributes to feelings of belonging and inclusion, which are considered fundamental human needs (Musiol \& Boehnke, 2013). Feeling understood by others (which is a possible outcome of value congruence) is associated with greater life satisfaction and fewer negative physical symptoms in the general population (Sortheix et al., 2013). 11. A relevant example is an exploration in Latin America where strong traditional values prevail (Garcia, Fuentes, Borrego, Gutierrez, \& Tapia, 2007). Values conflict itself has sustained a presence in the regional economics literature, as exemplified by the conflict between community and capital outlined by Bluestone and Harrison (1982). The same conflict continues to be deeply embedded in transitional regions such as contemporary Wales where community culture traits remain negatively associated with an economic culture associated with economic success (Huggins \& Thompson, 2015). A similar conflict of values underscores Syssner's conceptualizations of culture and identity in regional policy (Syssner, 2009).

12. The Helsinki-Uusimaa region has the NUTS-3 level coding of FI1B1, which is defined as metropolitan Finland in this paper. The term 'non-metropolitan Finland' is used to refer to the other remaining 19 NUTS-3 regions combined. (NUTS $=$ Nomenclature des Unités Territoriales Statistiques.)

13. The respondent's domicile or settlement is a self reported measure. The ESS12 questionnaire (F5, card 47) asks:

Which phrase on this card best describes the area where you live? A big city 1, the suburbs or outskirts of a big city 2, a town or small city 3 , a country village 4 , a farm or home in the countryside 5 . DK, 8.

(ESS12 Questionnaire, pp. 56-57)

Previous studies have found a varying degree of correspondence between people's choice of the most appropriate characterization of their domicile and the categories an analyst of official statistics would use, as pointed out in the critique of Sørensen (2014) by Shucksmith, Cameron, Merridew, and Pichler (2009). Both studies use the European Value Survey (EVS) rather than the ESS.

14. For comparisons of this distribution with those of other countries, as well as comparisons of alternative measures of well-being and country rankings, see the World Happiness Report by Helliwell et al. (2011). For a comparison of Finland with the Europe-wide figures for life satisfaction and happiness, see p. 56 in the third World Happiness Report, also by Helliwell et al. (2015).

15. We have reversed the six-to-one coding of item identification in the original guide of Schwartz (2012) to a one-to-six scale in order to associate higher numbers with more intense idenfication with the value. In their study of Finland in 2006, Bobowik et al. found a positive correlation between life satisfaction and values in the case of benevolence and conformity and negative correlations with power and achievement, as we do below using the 2012 survey (Bobowik, Basabe, \& Paez, 2014b, tab. 1, p. 7059).

16. The application of OLS regression to Likert life satisfaction scales is now routine (e.g., Helliwell \& Putnam, 2004). For a methodological discussion, see Kristoffersen (2010) and Ferrer-i-Carbonell and Frijters (2004).

17. What is as yet unclear here is the degree to which the association between metropolitan residence and certain extrinsic values is a result of selective migration or as a result of adaptation to a prevailing or pre-existing set of values present in such centres. Any differentiation of the two of selection and adaptation - would require longitudinal studies that collect both values and location.

18. See note 17 above.

\section{SUPPLEMENTAL DATA}

Supplemental data for this article can be accessed at https:/ doi.org/10.1080/00343404.2017.1331036.

\section{ORCID}

Philip S. Morrison (i) http://orcid.org/0000-0003-14489807

Mikko Weckroth (1) http://orcid.org/0000-0002-1697-2125

\section{REFERENCES}

Albouy, D. (2008). Are big cities really bad places to live? Improving quality-of-life estimates across Cities (Working Paper). Cambridge, MA: National Bureau of Economic Research (NBER).

Aslam, A., \& Corrado, L. (2012). The geography of well-being. Journal of Economic Geography, 12, 627-649. doi:10.1093/jeg/ lbr041

Bache, I., Reardon, L., \& Anand, P. (2016). Wellbeing as a wicked problem: Navigating the arguments for the role of government. Journal of Happiness Studies, 17, 893-912. doi:10.1007/s10902015-9623-y

Ballas, D. (2008). Geographical modelling of happiness and wellbeing. BURISA, 177(September), 12-17. Retrieved from http:// laria.org.uk/wp-content/uploads/2014/03/177.pdf

Ballas, D., \& Tranmer, M. (2012). Happy people or happy places? A multilevel modeling approach to the analysis of happiness and wellbeing. International Regional Science Review, 35, 70-102. doi: $10.1177 / 0160017611403737$

Becchetti, L., Bruni, L., \& Zamagni, S. (2015). Human values, civil economy, and subjective well-being. In J. Helliwell, R. Layard, \& 
J. Sachs (Eds.), World happiness report 2015 (pp. 134-151). New York: United Nations Sustainable Development Solutions Network (SDSN).

Berry, B. J. L., \& Okulicz-Kozaryn, A. (2009). Dissatisfaction with city life: A new look at some old questions. Cities, 26, 117-124. doi:10.1016/j.cities.2009.01.005

Berry, B. J. L., \& Okulicz-Kozaryn, A. (2011). An urban-rural happiness gradient. Urban Geography, 32, 871-883. doi:10.2747/ 0272-3638.32.6.871

Bluestone, B., \& Harrison, B. (1982). The deindustrialisation of America. Plan closing, community abandonment and the dismantling of basic industry. New York: Basic.

Bobowik, M., Basabe, N., Paez, D., Jimenez-Aristizabal, A., \& Bilbao, M. A. (2011). Personal values and well-being among Europeans, Spanish natives and immigrants to Spain: Does the culture matter? Journal of Happiness Studies, 12, 401-419. doi:10.1007/s10902-010-9202-1

Bobowik, M., Basabe, N., \& Paez, D. (2014a). Well-being and values of immigrants to Spain. In A. C. Michalos (Ed.), Encyclopaedia of quality of life and wellbeing (pp. 7074-7079). Amsterdam: Springer.

Bobowik, M., Paez, D., \& Basabe, N. (2014b). Well-being and personal values in Europe. In A. C. Michaelos (Ed.), Encyclopaedia of quality of life and well-being research (pp. 7056-7062). London: Springer Science + Business Media Dondrocht.

Botzen, K. (2016). Social capital and economic well-being in Germany's regions: An exploratory spatial analysis'. Region, 3, 1-24. doi:10.18335/region.v3i1.73

Brereton, F., Clinch, P., \& Ferreira, S. (2008). Happiness, geography and the environment. Ecological Economics, 65, 386-396. doi:10. 1016/j.ecolecon.2007.07.008

Chen, J., Davis, D. S., Wu, K., \& Dai, H. (2015). Life satisfaction in urbanizing China: The effect of city size and pathways to urban residency. Cities, 49, 88-97. doi:10.1016/j.cities.2015.07.011

Cummins, R. A., Davern, M., Okerstrom, E., Lo, S. K., \& Eckersley, R. (2005). Australian unity wellbeing index. Special report on city and country living (Report No. 12.1). Melbourne: School of Psychology and Australian Centre on Quality of Life, Deakin University.

Davidov, E., Schmidt, P., \& Schwartz, S. H. (2008). Bringing values back in: The adequacy of the European Social Survey to measure values in 20 countries. Public Opinion Quarterly, 72, 420-445. doi:10.1093/poq $/ \mathrm{nfn} 035$

Dobewall, H., \& Strack, M. (2014). Relationship of Inglehart's and Schwartz's value dimensions revisited. International Journal of Psychology, 49, 240-248. doi:10.1002/ijop.12004

Dunlop, S., Davies, S., \& Swales, K. (2016). Metropolitan misery: Why do Scots live in 'bad places to live?' Regional Studies, Regional Science, 3, 379-398. doi:10.1080/21681376.2016.1209981

European Commission. (2013). Quality of life in cities. Flash Eurobarmeter 366. Luxembourg: European Union.

European Social Survey (ESS). (2006). Final source questionnaire (round 3, 2006/7) amendment 03. Retrieved from https://www. europeansocialsurvey.org/docs/round3/fieldwork/source/ESS3_ source_main_questionnaire.pdf

European Social Survey (ESS). (2012). ESS6 - 2012 data download. Retrieved from http://www.europeansocialsurvey.org/data/ download.html? $\mathrm{r}=6$

Ferrer-i-Carbonell, A., \& Frijters, P. (2004). How important is methodology for the estimates of the determinants of happiness? Economic Journal, 114, 641-659. doi:10.1111/j.1468-0297.2004. 00235.x

Fischer, C. S. (1973). Urban malaise. Social Forces, 52, 221-235. doi:10.2307/2576376

Frey, B. S., \& Stutzer, A. (2002). Happiness and economics: How the economy and institutions affect buman well being. Princeton: Princeton University Press.
Fulmer, C. A., Gelfand, M. N., Kruglanski, A. W., \& Al, E. (2010). On 'feeling right' in cultural contexts: How person-culture match affects self-esteem and subjective well-being. Psychological Science, 21, 1563-1569. doi:10.1177/0956797610384742

Garcia, J., Fuentes, N. C., Borrego, S. A., Gutierrez, M. D., \& Tapia, A. (2007). Values and happiness in Mexico: The case of the metropolitan city of Monterrey. In L. Bruni, \& P. L. Porta (Eds.), Handbook on economics of happiness (pp. 407-427). Cheltenham: Edward Elgar.

Gasper, D. (2007). Uncounted or illusory blessings? Competing responses to the Easterlin, Easterbrook and Schwartz paradoxes of well-being. Journal of International Development, 19, 473492. doi:10.1002/jid.1383

Gough, I., \& Arlister McGregor, J. (2007). Well-being in developing countries: From theory to research. Cambridge: Cambridge University Press.

Guterman, S. E. (1969). In defense of Wirth's 'urbanism as a way of life'. American Journal of Sociology, 74(5), 492-499. doi:10.1086/ 224682

Hardin, C. D., \& Higgins, E. T. (1996). Shared reality: How social verification makes the subjective objective. In E. T. Higgins \& R. M. Sorrentino (Eds.), Handbook of motivation and cognition, Vol. 3: The interpersonal context (pp. 28-84). New York: Guilford.

Helliwell, J. F., \& Putnam, R. D. (2004). The social context of wellbeing. Philosophical Transactions of the Royal Society B: Biological Sciences, 359, 1435-1446. doi:10.1098/rstb.2004.1522

Helliwell, J., Layard, R., \& Sachs, J. (2011). World happiness report. New York: Earth Institute, Columbia University.

Helliwell, J., Layard, R., \& Sachs, J. (2013). World happiness report 2013. New York: United Nations Sustainable Development Solutions Network (SDSN).

Helliwell, J., Layard, R., \& Sachs, J. (2015). World happiness report 2015. New York: United Nations Sustainable Development Solutions Network (SDSN).

Higgins, E. T. (2000). Making a good decision: Value from fit. American Psychologist, 55, 1217-1230. doi:10.1037/0003-066X.55.11.1217

Higgins, E. T. (2005). Value from regulatory fit. Psychological Science, 14, 209-213.

Huggins, R., \& Thompson, P. (2015). Culture and place-based development: A socio-economic analysis. Regional Studies, 49, 130-159. doi:10.1080/00343404.2014.889817

Huppert, F. A. (2009). Psychological well-being: Evidence regarding its causes and consequences. Applied Psychology: Health and Well-Being, 1, 137-164. doi:10.1111/j.1758-0854.2009. 01008.x

Inglehart, R. (1990). Culture shift in advanced industrial society. Princeton: Princeton University Press.

Itaba, Y. (2016). Does city size affect happiness? In T. Tachibanaki(Ed.), Advances in happiness research (pp. 245-273). Amsterdam: Springer.

Jarden, A. (2010). Relationships between personal values, and depressed mood and subjective wellbeing ( $\mathrm{PhD}$ thesis, Psychology), University of Canterbury, Christchurch.

Jokela, M. (2009). Personality predicts migration within and between U.S. states. Journal of Research in Personality, 43, 79-83. doi:10. 1016/j.jrp.2008.09.005

Jokela, M. (2013). Personality and the realisation of migration desires. In P. J. Rentfrow (Ed.), Geographical psychology: Exploring the interaction of environment and behaviour (pp. 71-87). Washington, DC: American Psychological Association (APA).

Jordan, B. (2008). Welfare and well-being: Social value in public policy. Bristol: Policy Press at the University of Bristol.

Kasser, T., \& Ahuyvia, A. (2002). Materialistic values and well-being in business students. European Journal of Social Psychology, 32, 137-146. doi:10.1002/ejsp.85

Kitchin, R. M. (1997). Relations between psychology and geography. Environment and Behavior, 29, 554-573. doi:10.1177/ 001391659702900406 
Kristoffersen, I. (2010). The metrics of subjective wellbeing: Cardinality, neutrality and additivity. Economic Record, 86, 98123. doi:10.1111/j.1475-4932.2009.00598.x

Lagas, P., Van Dongen, F., Van Rin, F., \& Visser, H. (2015). Regional quality of living in Europe. Region, 2, 1-26. doi:10. 18335/region.v2i2.43

Lenzi, C., \& Perucca, G. (2016a). Happiness in Romanian cities on the road from post-communism transition to EU accession. Region, 3, 1-22. doi:10.18335/region.v3i2.123

Lenzi, C., \& Perucca, G. (2016b). Are urbanised areas source of life satisfaction? Evidence from EU regions. Papers in Regional Science. doi:10.1111/pirs.12232

Lenzi, C., \& Perucca, G. (2016c). Life satisfaction across cities: Evidence from Romania. Journal of Development Studies, 52, 1062-1077. doi:10.1080/00220388.2015.1113265

Lindeman, M., \& Verkasalo, M. (2005). Measuring values with the short Schwartz's value survey. Journal of Personality Assessment, 85, 170-178. doi:10.1207/s15327752jpa8502_09

Lonnqvist, J. E., Walkowitz, G., Wichardt, P., Lindeman, M., \& Verkasalo, M. (2009). The moderating effect of conformism values on the relations between other personal values, social norms, moral obligation, and single altruistic behaviours. British Journal of Social Psychology, 48, 525-546. doi:10.1348/ $014466608 X 377396$

Lu, C., Schellenberg, G., Hou, F., \& Helliwell, J. F. (2015). How's life in the city? Life satisfaction across census metropolitan areas and economic regions in Canada. In Economic insights (pp. 1-11). Ottawa: Statistics Canada.

Lun, J., Kesebir, S., \& Oishi, S. (2008). On feeling understood and feeling well: The role of interdependence. Journal of Research in Personality, 42, 1623-1628. doi:10.1016/j.jrp. 2008.06.009

Lyubomirsky, S., Sheldon, K. M., \& Schkade, D. A. (2005). Pursuing happiness: The architecture of sustainable change. Review of General Psychology, 9, 111-131. doi:10.1037/10892680.9.2.111

Moisio, S., \& Paasi, A. (2013). From geopolitical to geoeconomic? The changing political rationalities of state space. Geopolitics, 18, 267-283. doi:10.1080/14650045.2012.723287

Morrison, P. S. (2007). Subjective wellbeing and the city. Social Policy Journal of New Zealand, 31, 74-103.

Morrison, P. S. (2011). Local expressions of subjective well-being: The New Zealand experience. Regional Studies, 45, 1039-1058. doi:10.1080/00343401003792476

Morrison, P. S. (2014). The measurement of regional growth and wellbeing. In M. Fischer, \& P. Nijkamp (Eds.), Handbook of regional growth (pp. 277-289). Berlin: Springer.

Motyl, M., Iyer, R., Oishi, S., Trawalter, S., \& Nosek, B. A. (2014). How ideological migration geographically segregates groups. Journal of Experimental Social Psychology, 51, 1-14. doi:10.1016/ j.jesp.2013.10.010

Musiol, A.-L., \& Boehnke, K. (2013). Person-environment value congruence and satisfaction with life. International Journal of Humanities and Social Science, 3, 57-65.

Oishi, S., Diener, E. F., Lucas, R. E., \& Suh, E. M. (1999). Crosscultural variations in predictors of life satisfaction: Perspectives from needs and values. Personality and Social Psychology Bulletin, 25, 980-990. doi:10.1177/01461672992511006

Ojala, J., Eloranta, J., \& Jalava, J. (2007). The road to prosperity: An economic bistory of Finland. Helsinki: Suomalaisen Kirjallisuuden Seura.

Organisation for Economic Co-operation and Development (OECD). (2014). How's life in your region? Measuring regional and local well-being for policy making. Paris: OECD.

Park, N., \& Peterson, C. (2010). Does it matter where we live?: The urban psychology of character strengths.. American Psychologist, 65, 535-547. doi:10.1037/a0019621
Piper, A. T. (2015). Europe's capital cities and the happiness penalty: An investigation using the European Social Survey. Social Indicators Research, 123, 103-126. doi:10.1007/s11205-0140725-4

Pittau, M. G., Zelli, R., \& Gelman, A. (2010). Economic disparities and life satisfaction in European regions. Social Indicators Research, 96, 339-361. doi:10.1007/s11205-009-9481-2

Plaut, V. C., Lachman, M. E., \& Markus, H. R. (2002). Place matters: Consensual features and regional variation in American wellbeing and self. Journal of Personality and Social Psychology, 83, 160-184. doi:10.1037/0022-3514.83.1.160

Rentfrow, P. J. (2014). Introduction. In P. J. Rentfrow (Ed.), Geographical psychology: Exploring the interaction of environment and behaviour (pp. 3-11). Washington, DC: American Psychological Association (APA).

Rentfrow, P. J., Gosling, S. D., \& Potter, J. (2008). A theory of the emergence, persistence, and expression of geographic variation in psychological characteristics. Perspectives on Psychological Science, 3, 339-369. doi:10.1111/j.1745-6924.2008.00084.x

Ryan, R. M., \& Deci, E. L. (2000). Self-determination theory and the facilitation of intrinsic motivation, social development, and wellbeing. American Psychologist, 55, 68-78. doi:10.1037/0003066X.55.1.68

Sagiv, L., Roccas, S., \& Hazan, O. (2004). Value pathways to wellbeing: Healthy values, valued goal attainment, and environmental congruence. In A. Linley, \& J. Stephen (Eds.), Positive psychology in practice (pp. 68-85). New York: Wiley.

Sagiv, L., \& Schwartz, S. H. (2000). Value priorities and subjective wellbeing: Direct relations and congruity effects. European Journal of Social Psychology, 30, 177-198. doi:10.1002/(SICI)1099-0992 (200003/04)30:2<177::AID-EJSP982>3.0.CO;2-Z

Schwanen, T., \& Wang, D. (2014). Well-being, context, and everyday activities in space and time. Annals of the Association of American Geographers, 104, 833-851. doi:10.1080/00045608. 2014.912549

Schwartz, S. (2012). Computing scores for the 10 human values. European Social Survey. Retrieved from https://www.europeansoci alsurvey.org/docs/methodology/ESS1_human_values_scale.pdf

Schwartz, S. H. (1992). Universals in the content and structure of values: Theory and empirical tests in 20 countries. In M. Zanna (Ed.), Advances in experimental social psychology (pp. 165). New York: Academic Press.

Schwartz, S. H. (2004). Basic human values: Their content and structure across countries. In A. Toamayo \& J. Porto (Eds.), Valores e trabalho [Values in Work] (pp. 21-55). Brasilia: Editora Universidade de Brasilia.

Scott, K. (2012). Measuring wellbeing. Towards sustainability? London: Routledge.

Searle, B. A. (2008). Well-being: In search of a good life? Bristol: Policy Press.

Shields, M., \& Wooden, M. (2003). Investigating the role of neighbourhood characteristics in determining life satisfaction (Melbourne Institute Working Paper No. 24/03). Melbourne: Melbourne Institute of Applied Economic and Social Research.

Shucksmith, M., Cameron, S., Merridew, T., \& Pichler, F. (2009). Urban-rural differences in quality of life across the European Union. Regional Studies, 43, 1275-1289. doi:10.1080/ 00343400802378750

Simmel, G. (1976). The metropolis and mental life. New York: Free Press.

Smarts, E. (2012). Well-being in London: Measurement and use (GLA Economics Current Issues Note 35) (pp. 1-22). London: Mayor of London/Greater London Authority. Retrieved from https://www.london.gov.uk/sites/default/files/gla_migrate_files_ destination/cin35_0.pdf

Sortheix, F. M., Olakivi, A., \& Helkama, K. (2013). Values, life events, and health: A study in a Finnish rural community. 
Journal of Community and Applied Social Psychology, 23, 331-346. doi:10.1002/casp. 2125

Sørensen, J. F. L. (2014). Rural-urban differences in life satisfaction: Evidence from the European Union. Regional Studies, 48, 14511466. doi:10.1080/00343404.2012.753142

Stiglitz, J. E., Sen, A., \& Fitoussi, J.-P. (2009). Report by the Commission on the Measurement of Economic Performance and Social Progress. Commission on the Measurement of Economic Performance and Social Progress (CMEPSP). Retrieved from http://library.bsl.org.au/jspui/bitstream/1/1267/1/Measurement _of_economic_performance_and_social_progress.pdf

Syssner, J. (2009). Conceptualizations of culture and identity in regional policy. Regional and Federal Studies, 19, 437-458. doi:10.1080/13597560902957518

Tam Cho, W. K., Gimpel, J. G., \& Hui, I. S. (2013). Voter migration and the geographic sorting of the American electorate. Annals of the Association of American Geographers, 103, 856-870. doi:10. 1080/00045608.2012.720229

Tomaney, J. (2015). Region and place III: Well-being. Progress in Human Geography, 41, 99-107.

Tönnies, F. (1887). Gemeinschaft und Gesellschaft. Leipzig: Fues's; 2nd ed. 1912, 8th ed. Leipzig: Buske, 1935; repr. Darmstadt: Wissenschaftliche Buchgesellschaft, 2005. Translated in 1957 as Community and Society.

Valdmanis, V. G. (2015). Factors affecting well-being at the state level in the United States. Journal of Happiness Studies, 16, 985997. doi:10.1007/s10902-014-9545-0

Weber, M. (1921). Economy and society. Los Angeles: University of California Press.

Wirth, L. (1969). Urbanism as a way of life [1938]. In R. Sennett (Ed.), Classic essays on the culture of cities (pp. 165-170). New York: Appleton-Century-Crofts. 